\title{
REPERTORIO, AUTOR, LECTOR Y MERCADO EDITORIAL EN EL BRASIL DE 1970-1980: PRINCIPALES DINÁMICAS
}

\author{
POR \\ M. CARmen Villarino PARdo \\ Grupo Galabra-Universidad de Santiago de Compostela
}

Cuando se cumplían 50 años del Golpe de 1964 en Brasil, el escritor Luiz Ruffato organizó el libro Nos idos de março. Con el subtítulo de "A ditadura militar na voz de 18 autores brasileiros," reúne textos de dieciocho escritores/as que han vivido de un u otro modo la dictadura brasileña. Entre ellos, se encuentra Luiz Fernando Emediato, periodista, escritor y fundador, en 1992, de Geração Editorial en la que aparece esta colectánea de cuentos.

El libro no es simplemente un producto más en un año de efemérides porque Ruffato, con una posición destacada en el campo literario brasileño y un elevado capital simbólico (como escritor y como organizador de antologías), había sido ya el responsable -y autor del prefacio-del libro de Emediato, Trevas no paraíso. Histórias de amor e guerra nos anos de chumbo (2004), en el que reedita cuentos de la década de 1970.

Emediato, que tuvo textos premiados y publicados por algunas de las editoras en la línea del contrarrégimen en los años 1970 y 1980 (Codecri o Alfa-Ômega) y trabajó para periódicos de la llamada prensa alternativa (O Pasquim o Movimento), abandonó durante varias décadas el oficio de escritor de ficción. Ruffato, en coautoría, publicó-en ese año 2004 y en la misma editora-Fora da ordem e do progresso, primer volumen de la colección "Histórias do Brasil: Política" que pretende abordar la formación política del país a través de cuentos de productores/as literarios/as de diferentes momentos (incluídos autores/as presentes en el libro de 2014 como Ivan Ângelo, Ignácio de Loyola Brandão, Emediato, Júlio César Monteiro Martins, João Gilberto Noll, Domingos Pellegrini, Nélida Piñon o Sérgio Sant'Anna).

Cuando Ruffato entra en el campo literario brasileño, en 1979, Emediato ya ocupa posiciones de centralidad, habiendo participado en libros cuyas ventas superaron los 30,000 ejemplares (como el Histórias de um novo tempo, de 1977). Ese final de la década de 1970 e inicio de la siguiente coincide, además de con el fin del AI-5, con una serie de debates en periódicos y publicaciones especializadas sobre la consideración del libro como mercancía o producto cultural, el perfil del lector brasileño o los consumos 
culturales, cuestiones que abordaremos. Trataremos de entender dinámicas sistémicas que, en términos de Itamar Even-Zohar, evidencian elementos de repertorio, institución y mercado; sobre todo las concernientes a ese período en que el campo literario ocupó posiciones heterónomas en relación al campo del poder político (Bourdieu).

A través de los casos referidos de Emediato y Ruffato se pretende abordar la hipótesis de que en los últimos cincuenta años es posible identificar dinámicas relativas a la consideración del libro, del escritor y del mercado editorial enfocando diferentes vertientes de la ficción política brasileña.

\section{Emediato y RufFato, a Ambos LAdos DEL ESPEJO}

Ruffato ha adoptado diferentes y variadas tomas de posición (Bourdieu 3-46) a lo largo de su trayectoria como escritor. Además de ser el autor de diversas obras premiadas, ${ }^{1}$ se ha convertido en un reconocido organizador de antologías, con diversas propuestas repertoriales, que le han proporcionado también un importante capital simbólico en tareas de mediación y legitimación autoral, tanto en Brasil, ${ }^{2}$ como fuera del país. ${ }^{3}$

Su proyección internacional se debe, fundamentalmente, a traducciones de varias de sus obras a diferentes lenguas (español, alemán, francés, italiano o inglés) y su participación en numerosos eventos internacionales; con un momento de gran centralidad cuando profirió uno de los discursos de apertura-con amplia crítica y repercusión mediática, dentro y fuera de Brasil según Leonardo Neto-de la participación brasileña como país invitado de honor en la Feria internacional del Libro de Fráncfort, en 2013.

De modo que, en 2014, cuando publica Nos idos de março-con dieciocho cuentos de autores y autoras que han vivido la dictadura brasileña a lo largo de los años, de modo directo o indirecto (excepto Fernando Bonassi y Paloma Vidal, todos los demás la han vivido en términos biográficos y han escrito durante aquel período), ${ }^{4}$-el autor de Cataguases actúa como el escritor profesional que, desde 2003, se dedica en exclusiva

1 Entre ellas, Eles eran muitos cavalos (2001), la pentalogía de O inferno provisório (entre 2005 y 2011), o Estive em Lisboa e lembrei de você (2009).

2 Por ejemplo, Vinte mulheres que estão fazendo a nova literatura brasileira (2004) y +30 mulheres que estão fazendo a nova literatura brasileira (2005) en la editora Record; y varias colectáneas de la colección Língua Franca-que coordina en la editora Língua Geral-ofreciendo "uma reflexão sobre a história política e social do Brasil por meio de contos” (http://www.linguageral.com.br/questao-de-peleorganizacao-de-luiz-ruffato/).

3 Véase Villarino Pardo y Ruffato, O conto brasileiro contemporâneo (2011); Ruffato, Der Schwarze Sohn Gottes: 16 Fussballgeschichten aus Brasilien (2013); Ruffato, Brésil 25: 2000-2015 (2015).

4 Antonio Callado, Wander Piroli, Roberto Drummond, Ignácio de Loyola Brandão, Ivan Ângelo, Nélida Piñon, Sérgio Sant'Anna, Flávio Moreira da Costa, Frei Betto, João Gilberto Noll, Maria José Silveira, Roniwalter Jatobá, Domingos Pellegrini, Luiz Fernando Emediato, Luiz Roberto Guedes, Julio César Monteiro Martins, Fernando Bonassi y Paloma Vidal, por esta orden. 
al oficio, entendiéndolo no solo como producción de obras propias sino también como organizador de festival literario, responsable de colectáneas de textos, consultor editorial, columnista o conferenciante.

Si observamos las dinámicas actuales del campo literario brasileño, con productores/ as literarios/as de diferentes épocas que asumen de diversos modos la profesión de escribir, puede no resultar extraña una trayectoria profesional como la de Ruffato. Pero coincidimos con Luciene Azevedo respecto a que, a pesar de que las condiciones actuales de Brasil son más favorables para la profesionalización del escritor brasileño, "não deixa de impressionar o ainda reduzido número de escritores que podem 'viver de literatura' no país" (1). Este tema, de plena actualidad, también fue objeto de atención y debate en las décadas de 1970 y 1980 cuando, en el período final de la dictadura, se produjo una ampliación y una mayor visibilidad de productores/as que integraban el campo literario. Esa situación de "cierta euforia" (Pellegrini, Gavetas 125) lanzó al mercado autores/as nuevos/as; surgen nuevas editoras y numerosas revistas literarias, de corta duración, en la secuencia de nuevas dinámicas editoriales (Ficção, Escrita, José, Saco, Inéditos, etc.); ${ }^{5}$ se organizan encuentros y debates entre escritores, a partir de 1975 (Villarino Pardo, "Encontros" 151-68) y coincide con la consolidación del cuento como el género con mayor repercusión en el momento. ${ }^{6}$

En ese contexto, Emediato publica, en 1977, su primer libro-de cuentos y novela-Não passarás o Jordão, en la paulista Alfa-Ômega, casa editorial fundada en 1973 ( Maués 155-71; F. Maués 91-104; Reimão, Maués y Nery 171-90) y, según el investigador Malcolm Silverman, "a primeira editora intelectual de esquerda do país" (43). Aún hoy, tras más de cuatro décadas en activo, mantiene viva su "misión", como puede verse en su página web: "Há 43 anos publicando o pensamento crítico brasileiro" (http://site.alfaomega.com.br/).

Tras una reconocida trayectoria como escritor en los años 70 y como periodista (1973-1990), Emediato fundó en São Paulo, en 1992, la editora Geração Editorial, que se presenta como "uma editora de verdade" (http://geracaoeditorial.com.br/a-editora/), y que, según él mismo, procura provocar e intenta parecerse a lo que representaron editoras como José Olympio, Civilização Brasileira y Brasiliense, en sus respectivas épocas. Geração Editorial, con una trayectoria ya consolidada en la actualidad (y con títulos polémicos y comerciales en su catálogo, como Mil dias de solidão. Collor bateu e levou, de Cláudio Humberto Rosa e Silva), publica Trevas no paraíso (2014),

\footnotetext{
Varias de ellas (sobre todo, Escrita y fição) y su papel en el campo literario brasileño de los años 70 han sido analizadas por el propio Ruffato para su columna en la revista Rascunho (http://rascunho.com. br/autor/luiz-ruffato/page/2/).

6 Año de implantación de la Política Nacional de Cultura, formulada por el Ministro Ney Braga (Süssekind 22; Pellegrini, "Relíquias" 154-55).
}

\begin{tabular}{l}
-111 \\
\hline ISSN 0034-9631 (Impreso)
\end{tabular} 
los textos de Emediato organizados por Ruffato, y las colectáneas Ordem e progresso (2004, de Luiz Ruffato y Simone Ruffato) y Nos idos de março (2014), ambas con motivo de los 40 y 50 años del golpe de 1964, respectivamente.

Emediato y Ruffato, ambos de Minas Gerais, se afirman en dos momentos diferentes en términos de dinámicas sistémicas. El primero ocupó posiciones de centralidad en el campo literario brasileño en la década de 1970 mientras el segundo entra en el mismo en 1979, con la publicación de $O$ homem que tece-libro de poemas en mimeógrafo-el cual, sin embargo, no le proporcionó visibilidad, como prueba el hecho de que aparece raramente referido como su primer producto literario (Villarino Pardo, "Eles" 157-58).

Sin embargo, en 2004, cuando se publica el libro de Emediato Trevas no paraíso será el prestigiado autor de Eles eram muitos cavalos y de varias antologías de cuentos quien "rescate" y transfiera su capital simbólico al Emediato que dejó de publicar cuentos en la transición de los años 70 a los 80 y adoptó otras tomas de posición como periodista, editor o director de cine, perdiendo, por lo tanto, referencias en su posición como escritor en el campo literario. En el prefacio a la obra, que Ruffato titula "Por que ler Emediato, hoje?", se rehace parte de la trayectoria literaria de su colega de Minas y explica el principal objetivo de la publicación del libro: "Foi com o intuito de recuperar o autor para as novas gerações que propus a publicação deste volume" (Ruffato, "Por que" 16).

Ruffato destaca que Emediato había ocupado una posición de relativa centralidad en el campo literario brasileño de la década de 70 como joven autor de cuentos (nacido en 1951) y premiado en diferentes concursos (Ruffato, "Por que" 9-10). Así, "tendo escrito a quase totalidade de seus contos entre 1974 e 1978, nesse período Emediato obteve incríveis 25 premiações literárias" (Pereira 103); incluídos los más importantes del momento (sobre todo, el del Estado de Paraná, que ganó en 1971 como "Autor revelação;" Ruffato, "Por que" 9). Tras publicar algunos cuentos en antologías y estrenarse en libro con el alegórico y violento Não passarás o Jordão (reeditado en 2013), lanza en 1978 Os lábios húmidos de Marilyn Monroe (publicado por Ática, con prefacio del reconocido Antônio Callado, autor de Quarup), con recurso a la alegoría, al realismo maravilloso y a lo cotidiano. En 1978 publica $A$ rebelião dos mortos, una colectánea de nueve cuentos "premiada en 1977 y prohibida en 1978" (Süssekind 44). El texto homónimo resultó ganador del Concurso de Literatura Cidade de Belo Horizonte pero, después del anuncio del premio, el Ayuntamiento se negó a editar el libro, como preveían las bases del concurso, y tampoco pagó la cuantía indicada. Tras este episodio, "a comissão organizadora do referido concurso passou a contar com um censor e Emediato empreendeu uma luta inglória, durante anos, para finalmente obter o prêmio e a publicação" (Ruffato, "Por que" 12; Pereira 103).

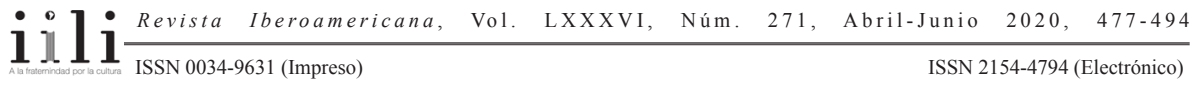


Se convirtió, así, en uno de los autores cuyos libros fueron censurados entre 1968 y 1978 (Pereira 103; Reimão, "Proíbo" 75-90), ${ }^{7}$ optando, en su caso, por adoptar-en la década siguiente-otras tomas de posición en el campo periodístico. Se trata, como señala Ruffato, de un "autor reestreante" (Ruffato, "Por que" 9), un Emediato que, como leemos en las solapas de Trevas no paraíso, "fustigou a moral burguesa e a ditadura militar sem parar, de 1973 a 1979, numa série de histórias irreverentes, explosivas e indignadas, carregadas de vigor e heroísmo, muitas delas censuradas, geralmente sob o argumento de que eran 'atentatórias' à moral e aos bons costumes" (Ruffato, "Por que" 9).

El interés de Ruffato por Emediato y otros autores y autoras que han vivido la dictadura no desentona con sus tomas de posición como escritor profesional (ya sea en algunas de sus obras literarias, en ferias/festivales o como organizador de varias antologías), que han marcado su actual posición en el sistema literario brasileño e internacional. En ese mismo año en que Ruffato entra en el campo literario brasileño, Emediato, un autor "polémico" y con un capital simbólico importante en aquel momento, declara en una entrevista de mayo de 1979 para el suplemento Tribuna da Imprensa -como recoge Ruffato en "Por que ler Emediato" (14)-, que renuncia temporalmente al cuento. Y, en 1984, cuando Ruffato publica Cotidiano do medo, su segundo libro de poemas (Villarino Pardo, "Eles" 157), Emediato lanza Verdes anos, una obra agotada en menos de un año, en que pretendía recuperar historias del momento y que reaparece, en parte, en Trevas no paraíso, la obra de Emediato prefaciada por Ruffato en 2004.

A partir de algunas de las tomas de posición de estos dos productores literarios pretendemos entender cuestiones relativas a autoría, libro, lector, mercado editorial y repertorio (género, temas) en esos años de transición entre la década de 1970 y 1980 en el sistema literario brasileño.

\section{DinÁmicAs EN El SiSTEMA Literario BRASILEÑo EN EL CAMBio DE DÉCADA: 1970-1980}

Como sabemos, el cuento fue un género priorizado por autores (y autoras) y lectores/as en las décadas de 1960 y 1970 en Brasil (Bastos 111). Según Fábio Lucas, era un momento en que "o público e as instituições se mostravam receptivos para com o gênero" (143). Así, el cuento fue adquiriendo la legitimación de que carecía dado que entre sus cultivadores se encontraban algunos de los autores con más prestigio en el

7 En el cuento "A data magna de nosso calendário cívico," incluído en Trevas do paraíso (2004) y en Nos idos de março (2014), el personaje del Diputado, en conversación con jóvenes intelectuales, comenta: "Sou frontalmente contrario à censura às obras literárias. Estas, por estarem veladamente situadas em estantes, não despertam a atenção geral. Nosso país é um país de analfabetos, senhores. A literatura não oferece perigo" (Emediato, "Trevas" 177; Ruffato, "Nos idos" 235).

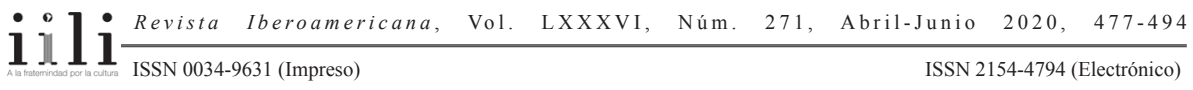


campo literario brasileño, en las revistas culturales y literarias se dedicaban páginas a su publicación y reseñas, $\mathrm{y}$, sobre todo, porque algunos integrantes de la institución (ciertas editoras, críticos, mercado y publicaciones periódicas) percibieron que el cuento podía vender y utilizaron los medios adecuados para prestigiar este material de repertorio, creando, para ello, premios que rápidamente adquieren reconocimiento público y social-por las cuantías económicas que ofrecen a los ganadores y, especialmente, por la posibilidad de publicar los textos seleccionados-y favoreciendo la creación de antologías colectivas.

El Concurso de Contos do Paraná dinamizó la producción literária y contribuyó, como estímulo, a la producción y revitalización del género. A pesar de algunos éxitos (por ejemplo, los libros Desastres de amor, de Dalton Trevisan, y Os 18 melhores contos do Brasil, de Bloch Editores, tenían importante demanda y figuraron, durante semanas, en las listas de los más vendidos) circulaba la idea de que el cuento no vendía.

\subsection{La consideración del libro y el oficio de escritor en el Brasil del cambio de década (1970-1980)}

Esta transición entre décadas coincide con un momento de cambios importantes en el espacio social brasileño, con el final del AI-5 y el inicio de la Apertura política en 1979, previos a los últimos años de dictadura. Hay evidentes reflejos de ello en las dinámicas que se viven en 1977, en que se suceden los manifiestos solicitando el final de la censura, se produce la entrada de las mujeres en la Academia Brasileira de Letras -con Rachel de Queiroz-y se celebran varios encuentros de escritores-como Cultur 77, en Porto Alegre, o el I Encontro com a literatura brasileira, en São Paulo-en los que se intentaba, en buena medida, cambiar una situación en la que se consideraba que ni el mercado interno ni el externo eran "receptivos à produção literária brasileira" (Medina 12). De hecho, según Cremilda Medina, la situación del mercado editorial interno era desoladora, ya que "uma população potencial de mais de 100 milhões de habitantes não consome edições de cinco mil exemplares de ficção e muito menos três mil livros de poesia" (12).

A inicios de los años 80, la discusión de la intelectualidad brasileña dejó, poco a poco, de centrarse en el enemigo común-la censura-para incluir otros problemas; sobre todo en el caso de algunos escritores que eran cada vez más conscientes de su oficio. Pasan a organizarse en sindicatos-aunque el de Rio de Janeiro y el de São Paulo fueron de los más visibles, no eran fuertes (Villarino Pardo, "Encontros" 154)-y a participar en varios encuentros con el público en diferentes lugares del país (Zilberman, "Brasil" 97; Villarino Pardo, "Encontros" 151-68) para desmitificar su figura de personas aisladas en un escritorio, lejos de la realidad, y atraer más lectores a través de sus intervenciones y charlas sobre el proceso de creación literaria o sobre su trayectoria personal. En esos

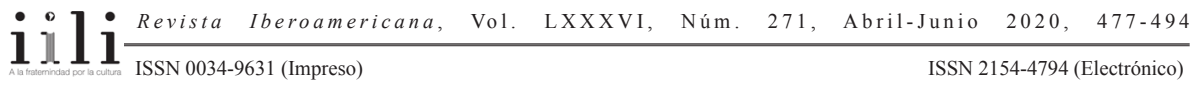


eventos se quejan de la escasez de lectores, de la mala distribución de los libros en el país, del precio del papel, de las tiradas reducidas, del menosprecio al escritor (sobre todo del autor nacional joven) y de una falta de atención al libro y a lo que lo rodea, que crean la imagen de que, como señala Silviano Santiago, se trata de "un objeto de lujo" (Santiago, Vale 26). ${ }^{8}$

Tânia Pellegrini, al analizar en 1996 esa situación, considera que, en la década de 1970 en Brasil, "a leitura ainda é um hábito de minorias" (Gavetas 76) debido a varias causas: una escolarización relativa; la renta familiar baja y el desempleo en aumento como estímulos para la "evasão da escola para o trabalho" (76); y señala también que "a indústria cultural é muito poderosa, notadamente a televisão, que compete mais diretamente com o hábito de leitura", además de que el precio del libro era cada vez más "proibitivo" (76). De modo que, concluye, "os compradores e/ou leitores de livros no Brasil constituem uma parcela reduzida da população" (76).

Esto mismo era percibido (e incluso denunciado) por los propios productores literarios. Así, en 1980, Ignácio de Loyola Brandão señalaba que cada vez había más "autores bons, dispostos a manter o ritmo e o espaço de relativa liberdade que se conquistou e que se deve lutar por não só manter, como expandir" ( $O$ Estado de São Paulo, "Caminhos" 34), pero que se vivía una situación de enorme precariedad en torno al libro, con precios elevados que lo convertían en un producto "destinado a uma elite consumidora" en un país con escasez de bibliotecas públicas y escolares y una red de librerías insuficiente (O Estado de São Paulo, "Caminhos" 34).

El cambio de década trajo también más dudas sobre el tema del libro en Brasil, especialmente intentando aventurar el rumbo de la producción editorial, cuyo estado había cambiado a final de los años 70 hacia una mayor industrialización y una cierta expansión. ${ }^{9}$ Se observa un interés amplio por reflejar y discutir en diferentes ámbitos (también en el literario) el momento presente y por conocer la realidad del país, no solo por parte de la intelectualidad sino también de un sector considerable de público.

Estas preocupaciones centraron varios artículos y debates en periódicos y revistas especializadas, sobre todo entre 1978 y 1980, coincidiendo con dos ediciones de la Bienal Internacional del Libro de São Paulo. ${ }^{10}$ Precisamente, el periódico $O$ Estado

8 Como apuntó Santiago, "O livro é, pois, objeto de classe no Brasil" (Vale 28), añadiendo que "a proporção de 60 mil leitores para 110 milhões de habitantes, já levantada por Roberto Schwarz em 1970 e retomada por Carlos Guilherme Motta em 1977, é 'ridícula e deprimente"' (Vale 25).

9 El periodista Moacir Amâncio comenta que, entre 1975 y 1980, se observa como "dezenas de autores que haviam parado de publicar recomeçaram. Outros saídos do ovo passaram a ser conhecidos. As editoras investindo nascendo" (21).

10 Tras la V Bienal do Livro de São Paulo, en 1978, leemos, a modo de balance: "uma verdade indiscutível: existe já entre nós uma indústria editorial que, se não atingiu ainda, está às vésperas da maioridade" ("V Bienial" 2). Ese destaque dado a esta situación se derivaba, en parte, del inusitado espectáculo

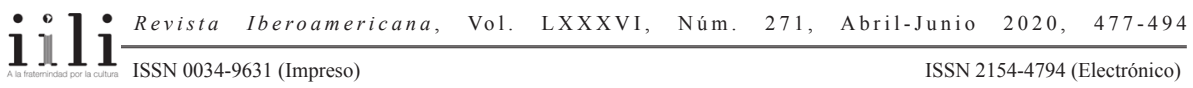


de São Paulo dedicó un especial al tema “Ofício de Escritor”, en 1978, durante la celebración de la V Bienal y, en ese mismo año, la nueva revista especializada Leia livros también reservó algunas de sus páginas a la consideración del producto libro. En este caso, destacamos "Um falso problema: cultura ou mercadoria”, texto del sociólogo y consultor editorial Pedro Paulo Poppovic, en el que intenta evidenciar la realidad de que "el brasileño no lee" y que la situación no muestra mejoría ni siquiera con el éxito de algunas publicaciones concretas (la mayoría comercializadas en quioscos o por algún club del libro). Pero el debate procura también enfocar cuales serían los canales más adecuados para la venta de libros, enfrentando dos posturas (tradicionalistas/ progresistas). Según Poppovic, para los más "tradicionalistas y pesimistas" la venta de estos productos fuera de las librerías se atribuye a motivos "menos dignos, como a busca de status, ficando subentendido que os livros comprados dessa forma, reduzidos à quantidade de mera mercadoria não são lidos. Vender livros assim não passa de um negócio" (22).

La otra perspectiva que el texto refleja estaría representada por aquellos que asumen una actitud, en su opinión, más "progresista" y que consideran el libro como una mercancía más, siendo así necesario desmitificar el producto literario y todo lo que lo rodea. De este modo, el libro pasaría a ocupar un espacio en las estanterías de supermercados, de tiendas de regalos y sería un producto más en la cesta de la compra, sujeto a las leyes del mercado editorial: buen aspecto externo, intensas campañas de marketing, consideración de los gustos del público, etc. ${ }^{11}$ Todo ello y más para rentabilizar las importantes inversiones que las industrias editoriales y gráficas estaban desarrollando (Jucá 42). Para estos "progresistas" el problema de los bajos índices de lectura en Brasil dependería, así, del vendedor por no conseguir ver los cambios y las nuevas oportunidades. Según Poppovic, buen conocedor de las dinámicas del campo editorial brasileño, lo mejor sería diversificar los canales de venta, adaptando los tipos de libro a las formas de comercialización: "Em suma, nem só livrarias, nem apenas supermercados" (22).

Por su parte, la serie publicada en O Estado de São Paulo se centró más en el oficio que en el producto. Contó con la participación de destacados escritores como Darcy Ribeiro, José Louzeiro, Ary Quintella, Nélida Piñon, Antônio Callado, Orígenes Lessa, J. J. Veiga o Antônio Torres (O Estado de São Paulo, "Escritores" 28). Todos ellos recuerdan sus inicios de carrera y señalan dificultades y problemas para la circulación de sus obras. Así, Piñon comenta que sus libros no eran bien comercializados por las

que significaba en ese momento, en Brasil, ver una exposición de cuatro kilómetros de libros y más de 200,000 visitantes, cuya finalidad es "contribuir para a ampliação do mercado interno, colocando o povo em contato com o livro" (Fittipaldi 7).

11 Por tanto, más que atender a las leyes internas del propio sistema literario, los productores y productos literarios se definirían más por la heteronomía que por la autonomía (ver Bourdieu 7).

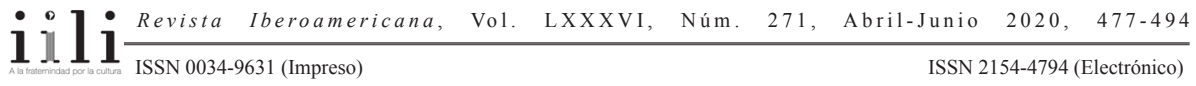


editoras pequeñas en que publicó durante años y que al cambiar a la editora Record, con Aforça do destino (1978), observa nuevas e interesantes estrategias de comercialización y venta. ${ }^{12}$ Entiende que el mercado proporciona una nueva perspectiva al escritor, que "percebeu que além da asfixia da censura, da asfixia do mercado, havia outra dificuldade: a de se colocar o livro brasileiro na livraria" (O Estado de São Paulo, "Escritores" 28). Louzeiro también coincide en que la publicación de sus primeras obras en editoras pequeñas le dio (a él y, en general, a los autores) la posibilidad de ser editado pero que, al carecer estas de condiciones económicas, dependen de otros para la distribución y no tienen condiciones "de imposição perante as organizações dos livreiros" (O Estado de São Paulo, "Escritores" 28).

Lo cierto es que las posibilidades que tenía un autor brasileño (y todavía más si era nuevo en el oficio) de ser publicado por una editora consolidada eran escasas; entrando en el campo literario, habitualmente, "pela porta dos fundos," como anota Antônio Torres (O Estado de São Paulo, "Escritores" 28). En el caso de Louzeiro, y como él mismo recordaba, "foi com o lançamento do romance Lúcio Flávio, o passageiro da agonia, que me tornei conhecido. Logo a seguir a censura me faria muita promoção, apreendendo o Aracelli, meu amor" (O Estado de São Paulo, "Escritores" 28). Se produce así, en cierta manera, un "efecto rebote" derivado de la actividad censoria; ya que, como anota Renato Franco, con frecuencia esas prohibiciones pueden "servir de estímulo para alguns artistas ou intelectuais criativos" (80).

En el caso de la editora Record, por ejemplo, su responsable-Alfredo Machadollegó a ser acusado por algunos intelectuales de publicar únicamente autores extranjeros (Davis 27) y de vender libros como se venden productos de hogar, porque, con el objetivo de conseguir buenas cifras de ventas, hizo una intensísima campaña de marketing para vender libros-fue la primera editora en obtener el Prêmio Destaque de Marketing de la Associação Brasileira de Marketing, en 1977 (Davis 27)-y consiguió, en el corto período de tres años, "vender um milhão e 31 mil exemplares da obra completa de Jorge Amado-composta de 24 livros" (Davis 27)-. Él mismo reconocía, en 1979, que "a publicação de best-sellers internacionais nos deu recursos financeiros e experiência para trabalhar com o escritor nacional. E hoje, dos 232 títulos que publicamos em 1978, 81 títulos, ou seja, 35\%, foram de autores nacionais" (Davis 27). Datos reveladores ya que, incluso en esas circunstancias, representaban únicamente un tercio del total.

12 También otros participantes se quejaron de lo mismo. Ary Quintella comentó que "o grande problema do mercado do livro brasileiro não é conseguir ser editado. A questão é ser vendido" ( $O$ Estado de São Paulo, "Escritores" 28); y José J. Veiga recuerda "que levei oito anos para me afirmar, simplesmente porque não houve condições de se fazer um trabalho correto de divulgação e distribuição, coisa que não existe até hoje. A distribuição é o nó do mercado dos escritores" ( $O$ Estado de São Paulo, "Escritores" 28).

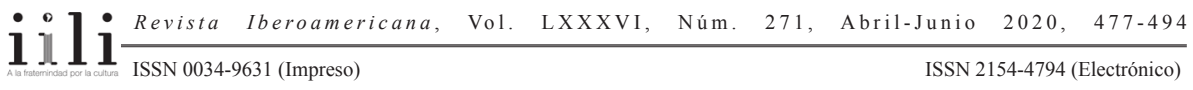


Conseguir ser publicado por una editorial prestigiada en el sistema literario implicaba, no pocas vezes, asumir una mayor dependencia del productor en relación a las condiciones impuestas por la editora-que integra también la institución dentro del sistema literario (Even-Zohar 37)-y a ocupar, a veces, posiciones heterónomas. ${ }^{13}$ En 1980, los estudios sobre el sector editorial revelan ya la existencia de un público consumidor amplio y de un número grande de títulos a disposición de los lectores. Así, entre 1977 y 1979 se había duplicado el número de títulos editados anualmente según Caio-Costa, que obligaba a los libreros a una inversión económica mayor para poder ofrecer una panorámica más amplia de la producción del momento. ${ }^{14}$

En 1979, el Ministro de Educación y Cultura, Eduardo Portella, creó el Programa de Desenvolvimento do Livro (Prodelivro), órgano del Ministério de Educação e Ciência-MEC-vinculado a la Fundação Nacional do Material Escolar (Fename). El Prodelivro preveía "coordinar a nivel nacional la producción y la difusión del libro en el país"; aunque estos objetivos fueron contestados por importantes agrupaciones de editores, libreros y escritores y entendidos por Louzeiro-en la época Primer Secretario del Sindicato dos Escritores do Rio de Janeiro (SERJ)-como una tentativa de "estatizar a produção e a comercialização de um tipo de veículo comunicador que andava à deriva do controle oficial" (Boletim 5). Tras un debate intenso, se amplió el Grupo de Assessoria e Participação do Prodelivro (GAP) que, al cabo de varios meses de reuniones, emitió un informe proponiendo medidas y sugerencias para mejorar algunos de los elementos problemáticos en el sector del libro: distribución, derechos de autor, editoras (también en el caso de las extranjeras), librerías o promoción de la lectura (Costa 25).

Un número especial de la revista Leia livros en agosto de 1980 (en la época de la VI Bienal do Livro de São Paulo), muestra una detallada "anatomia do mercado brasileiro" ("Anatomia" 31) distinguiendo cuatro "grandes filones": el integrado por las publicaciones vendidas en quioscos ("é um dos maiores mercados"); el de libros didácticos ("enorme e rentável"); el de las ediciones "vendidas de porta em porta"; y el mercado de las tradicionales librerías-“"primo pobre dos outros três pois não existem quinhentas livrarias no país inteiro e se contarmos todos os locais em que se vendem livros (papelarias, viaturas da Fename, farmácias, etc.) não se cataloga mais do que mil e setecentos pontos de venda" ("Anatomia" 31). Aprovechando, de nuevo, la cita de la Bienal paulista, también el periódico O Estado de São Paulo (Lopes 44), promovió una serie de debates y encuentros para tratar estos asuntos, que atraían la atención de los diferentes sectores y agentes implicados (editores, escritores, representantes del Prodelivro, Câmara Brasileira do Livro, etc.).

13 El "dios rabioso del mercado" que refiere Silviano Santiago, para quien "Como deus, o mercado escreve certo por linhas artísticas tortas" (Vale 79).

14 Pellegrini confirma ya ese crecimiento a mediados de la década de 1970 ("Relíquias" 150-51). 


\subsection{Lanecesidad de conquistar el mercadonacional: cuestión también de repertorio}

El escritor nacional suele aparecer en ese tipo de referencias (encuentros, entrevistas o noticias de prensa) como una especie que debe ser protegida, a pesar de que, a partir de 1975, su situación mejorase bastante en la consideración social y por parte de agentes relacionados con el campo del poder. Loyola Brandão recuerda ese cambio en un artículo de febrero de 1979, cuando un grupo de escritores brasileños rompió con modos habituales - hasta entonces- "ao descer para a rua. Isto quer dizer que esses autores começaram a mostrar textos mais chão, mais reais, retratos de seu tempo e de seu lugar, documento e participação de sua época. Quanto ao público, começou a corresponder, embora timidamente..." (23). ${ }^{15}$

Esa perspectiva es compartida con Piñon quien, en 1979, a su regreso de un viaje de trabajo a Estados Unidos, también explica su visión de la situación del escritor brasileño en $O$ Estado de São Paulo. El autor de Zero, que considera a Piñon amiga, "batalladora de tantos seminarios de literatura por este País", entiende que su postura sintetiza "quase que em forma de lema, a filosofia de um grupo de escritores brasileiros que, a partir de 1975, 'desceram realmente para a rua', com seu corpo, sua palavra, seus textos, para um encontro pessoal, direto" (Brandão 23). Se abre un nuevo espacio de posibles y parece observarse una cierta correlación entre "proximidad del autor" e "interés del público".

Destaca Brandão que se trató de un momento muy importante "de desmitificación del escritor tradicional"; y que ese cambio "correspondeu imediatamente a um certo avanço do interesse popular pela literatura nacional. Avanço pequeno ainda, mas que pode se expandir ..." (Brandão 23). Una preferencia que sintetiza Sandra Reimão en "Fim da Década: Interesse pelo Brasil" (Reimão, Mercado 70), señalando que es más evidente en el sector editorial de "no ficción" que en el de la literatura ficcional. Crecía el mercado para un determinado tipo de editoras y se percibe que la "literatura política" pasa a ser un excelente negocio "no raiar da 'abertura"” (Hollanda y Gonçalves 53).

Si entre los títulos de éxito en el mercado predominaban, con sucesivas ediciones agotadas, los llamados "best-sellers da não ficção", también las obras ficcionales (especialmente aquellas que escogían materiales repertoriales similares y que contaban con consumidores homólogos) se beneficiaron del clima de semiapertura política. Así, al analizar los diferentes balances (Reimão, Mercado 70-85) de lo que fue la década

15 Un cambio confirmado también por el escritor gaucho Caio Fernando Abreu, quien señalaba 1975 como la fecha a partir de la cual "o escritor brasileiro parou de ser um desconhecido para o grande público" (166).

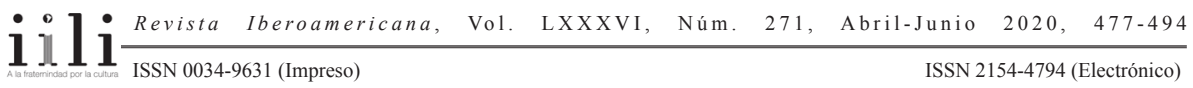


de 1970 para el sistema literario brasileño, ${ }^{16}$ caracterizada como "de muchos libros", el publicado por el Jornal do Brasil confirma que, en los años 70, hubo un aumento considerable del número de títulos de obras literarias en Brasil y añade que, aunque la mayor parte de esa producción corresponda a libros extranjeros, "raramente bem traduzidos, a verdade é que o autor nacional foi pouco a pouco ganhando a preeminência na programação editorial, até se chegar ao ponto de proclamar a ocorrência de uma explosão da literatura brasileira, principalmente na área do conto" ("Década" 27).

Esa situación mostró, para algunos, que el libro brasileño entraba en el circuito de las mercancías, como los jabones o los zapatos: "Produto à venda, sujeito mais que sempre às preferências de um público de classe média já condicionado ao gosto do fácil, do leve, do suave e às opções editoriais embasadas nas possibilidades de lucro rápido e seguro" (Pellegrini, Gavetas 127). Y al mismo tiempo, como sintetiza Marcelo Ridenti, en el cambio de década "florescia um mercado de oposição à ditadura nas classes médias, que a indústria cultural soube aproveitar a partir do fim dos anos 70" (350).

Los ingredientes para que esta tendencia tuviese éxito estaban servidos, porque se percibía una cierta homología entre un sector amplio del campo de producción, el mercado y los consumidores; había un público deseoso de conocer noticias que se le ocultaban o que solo aparecían referidas indirectamente, periodistas con interés en mostrar y un canal que, en paralelo a la prensa, ofrecía una vía alternativa: la novela-reportaje.

En general, se trata de documentos de oposición, firmados por autores en otro momento activistas políticos, jóvenes y prácticamente inexperientes como escritores. De ello es buen ejemplo el libro de Fernando Gabeira $O$ que é isso, companheiro? (1979), porque la tendencia que inauguró, como ex-militante de organización de izquierdas que ofrece sus testimonios, fue seguida con éxito. Es un tipo de "narrativa testimonio" que algunos críticos no saben si denominar novela u otro nuevo género. ${ }^{17}$ Su éxito lo confirman los 80,000 ejemplares vendidos en ese mismo año 1979 (Reimão, Mercado 72) y el hecho de permanecer durante 86 semanas en la lista de las obras más vendidas (Pellegrini, Gavetas 37). Este "filón" (Reimão, Mercado 72) continuó, pero no en la misma intensidad, con otros textos de la llamada-con frecuencia-"literatura del yo", o "memorias", que alcanzó un público de clase media bastante independiente y, en general, apolítico (Pellegrini, Gavetas 37). En opinión de Silviano Santiago, el principal interés de este tipo de producción literaria es el de un "questionamento da história oficial, daquela história que nos foi contada, mas nos foi contada de maneira

${ }^{16}$ Según Pellegrini, lo que resulta evidente es el incremento de la "literatura estrangeira pasteurizada destinada ao entretenimento da classe média, na trilha da indústria cultural, tal como a tradução maciça de best-sellers americanos" (Gavetas 123).

${ }^{17}$ Para Pellegrini (Gavetas 35) un ejemplo de "livro testemunho documento-depoimento-memória" y para Reimão (Mercado 71) un texto situado en la "zona de interseç̧ão entre o chamado segmento ficcional e o não-ficcional".

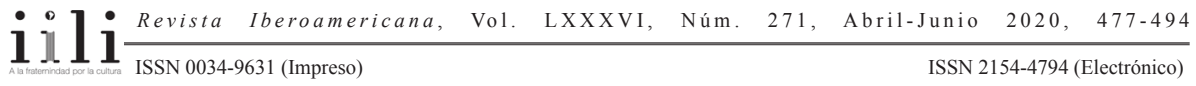


visivelmente influenciada pelo poder", y que denomina "a história dos vencidos" (Santiago, "Memorialismo" 251).

Por otro lado, para Flora Süssekind-y en buena medida también para Malcolm Silverman-esa popularidad de los libros de memorias, y, en menor medida, de la novela memorialística es posible que se deba a una necesidad de tipo catártico del lector y del escritor: "um grande mea culpa da classe média" (Süssekind 44).

\section{Síntomas de otros cambios}

Los años 80 fueron fundamentales en el camino hacia la dignificación del oficio de escritor, el crecimiento del sector editorial y la profesionalización del productor literario en Brasil. Este era un objetivo de un grupo amplio de autores/as, pero, como varios de ellos admitían en 1982 ("Escritores de briga" 60), el camino hacia la profesionalización todavía "é, no Brasil, uma simples picada aberta na floresta de maus usos e costumes". A pesar de que, como señalaba el escritor João Antônio, "já não se pode dizer que é sempre mau negócio lançar fiç̧ão de autor nacional" ("Escritores de briga" 60).

La industria editorial brasileña inició una expansión creciente (Pellegrini, "Relíquias" 163) y se aprecian algunos cambios en la relación entre escritor/editor, menos paternalista, con contratos y elementos de mediación entre ellos (incluida la presencia incipiente y progresiva de agentes literarios). Aunque algunos escritores y escritoras venían defendiendo una mayor profesionalización del oficio, ese tema provocó importantes discusiones, ya que había una cierta desconfianza ante el temor de que ello implicase una pérdida de libertad a la hora de escribir y una mayor dependencia en relación a las normas del mercado (Süssekind 88). Süssekind, que definió bien las dinámicas relativas a la década de 1970, no tiene dudas al mostrar los cambios que ofrecen los años 80 (además de otros relativos a la consideración más comercial del libro), que introducen otro elemento clave, "a lógica do mercado. Com isso, abre-se outra trilha igualmente dupla. Não a da censura, mas a da profissionalização" (90).

El análisis de esas lógicas del mercado del libro no han sido frecuentes en el ámbito de los estudios literarios, como demuestran Marisa Lajolo y Regina Zilberman (16467). En su libro O preço da leitura. Leis e números por detrás das letras explican, en parte, la historia del establecimiento de los derechos de autor y de algunos procesos de prácticas editoriales y profesionalización del escritor en Brasil-sobre todo en el siglo XIX-. Concluyen su recorrido con datos relativos a la década de 1990 y de sus investigaciones deducen que, en 2001, sin contar las ventas por internet (en un escenario todavía incipiente en relación a la situación actual), la "radiografía del universo de los libros" se mueve de modo diferente a la "linearidade do percurso autor >editor >gráfica>livraria>leitor" (164). Así mismo, en relación a los canales de distribución y comercialización del libro observan que, junto a los considerados "tradicionales"

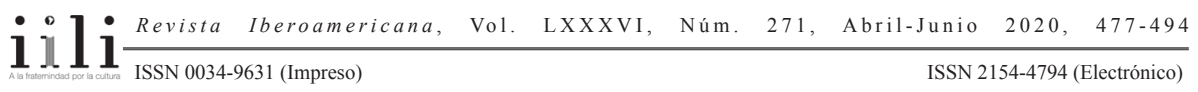


(librerías, papelerías, quioscos y supermercados), surgen otros-entonces considerados"no convencionales" (ferias y fiestas del libro, entre ellos) que contribuyen, también, a nuevas formas de consumo de lectura.

En cualquier caso, en un trabajo posterior, Zilberman comenta que, a pesar de la diferencia temporal, hay determinadas "iniciativas, bem sucedidas" en las dinámicas actuales de los campos literario y editorial que, en buena medida, tienen su inicio a finales de los años 70 (Zilberman, "Desafios" 186). Señala, entre ellas, la circulación de autores/as brasileños a través de encuentros con el público (no solo escolar) y su trabajo y lucha a favor de la democratización del país. Identifica varios desafíos para el productor literario en la actualidad: "la difícil profesionalización" (186-88), "la circulación entre escuelas, ferias de libros y fiestas literarias" (189-91), "fortalecimiento del mercado"(191-92), "innovación y renovación literaria" (193-95) y "à la recherche del mercado internacional" (195-99). ${ }^{18}$ De su diagnóstico se deduce que, en lo relativo a determinados aspectos de agentes y dinámicas del campo literario, el hoy del siglo XXI y el ayer (sobre todo de las décadas de 1970 y 1980), están muy relacionados en varias de estas dimensiones.

En buena medida esa perspectiva coincide con las observaciones de Pellegrini quien señala, en 2014, que el alcance de algunos procesos relativos a la industria cultural brasileña iniciados durante el período de la dictadura por agentes del campo de poder político junto con condicionantes a nivel internacional-de carácter capitalista-habían sido suficientemente fuertes como para "conseguir penetrar no coração da instância criativa, consolidando uma mudança de mentalidade-já em gestação anteriormentetambém na esfera literária, agora pautada indelevelmente pelas normas do mercado" ("Relíquias"166). De modo que, como también destaca, la consolidación de esa industria cultural consiguió establecer "parâmetros e paradigmas para as décadas subsequentes, já então direcionando a produção para diferentes 'nichos de mercado', tanto no que se refere aos temas quanto aos resultados formais" ("Relíquias" 167).

Coincido con estas apreciaciones y entiendo que los libros de Emediato y Ruffato analizados integran un mismo "nicho de mercado" que aquellos que, en este mismo siglo XXI, enfocan materiales repertoriales asociados a reflexiones sobre "a longa noite que se seguiu" (Ruffato, Nos idos 13) al período iniciado en 1964.

Se constata que el siglo actual no visibiliza al Ruffato de la década de 1970 y que el Ruffato actual trae luz sobre el Emediato de aquella época, en un proceso que nos permite descubrir dinámicas relativas a los campos literario, editorial y cultural de aquellos años en que se instauran esquemas mercantiles de producción cultural y literaria, consolidándose entonces una industria cultural brasileña a la sombra de la censura (Pellegrini, "Relíquias" 154). Emediato y Ruffato participaron en esos

18 Ver también, Villarino Pardo, “O espaço" 261-74.

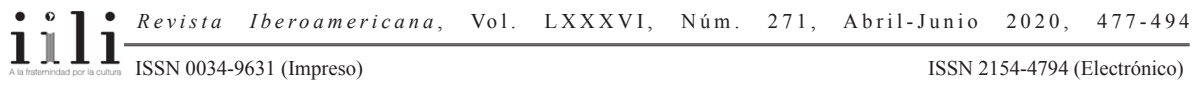


procesos y, en la actualidad, desde posiciones diferentes en el campo literario, integran un mercado editorial-el brasileño-que, en 2012, se configuró como el noveno a nivel mundial (Carrenho), y lo hacen mereciendo tiradas significativas que alcanzan muy importante volumen de ventas. ${ }^{19}$

\section{OBRAS CITADAS}

Abreu, Caio Fernando. “A ficção dos anos 70." Jornadas literárias. O prazer do diálogo entre autores e leitores. Tânia M. Rösing y Vera Teixeira de Aguiar, orgs. Prefeitura Municipal y Universidade de Passo Fundo, 1991. 165-70.

Amâncio, Moacir. "Literatura começa com sinal vermelho". Folha de São Paulo. 31 dic. 1980. Ilustrada 29.

“Anatomia do mercado brasileiro". Leia livros (1980): 31.

Azevedo, Luciene. "Daniel Galera: profissão, escritor". Revista Inventário 12 (2013): $1-12$.

Bastos, Alcmeno. “Aficção brasileira contemporânea.” Iberoromania 38 (1993): 111-18. Boletim do Sindicato dos escritores do Rio de Janeiro 4 (1980): 5.

Bourdieu, Pierre. "Le Champ Littéraire." Actes de la recherche en Sciences Sociales 89/1 (1991): 3-46.

Brandão, Ignácio de Loyola. “Autores, o momento é de lucidez.” Última Hora (5 feb. 1979): 23.

Carrenho, Carlo. "Brasil fica em $9^{\circ}$ lugar em ranking global de mercados editoriais". Blog Publishnews. 8 oct. 2012.<https://publishnews.wordpress.com/2012/10/08/ brasilnonolugar/>. 21 sept. 2016.

Costa, Caio Túlio."Um dia a casa cai”. Leia livros 1 (1978): 30.

Davis, Ana. "Alfredo Machado: Vendo livros como quem vende sabão em pó”. Jornal do Commercio (7 enero 1979): 27.

Emediato, Luiz Fernando y otros. Histórias de um novo tempo. São Paulo: Codecri, 1977. Trevas no Paraíso. Histórias de amor e guerra nos anos de chumbo. São Paulo: Geração Editorial, 2004.

"Escritores de briga." Isto É (12 mayo 1982): 60.

O Estado de São Paulo. "Os caminhos da ficção nacional em tempos de Abertura" (20 julio 1980): 7.

“Os escritores insistem: o livro é uma mercadoria”. O Estado de São Paulo. (20 ago. 1978): 28.

${ }^{19}$ Hasta finales de octubre de 2016 se han vendido 8,000 de los 10,000 ejemplares de Trevas no Paraíso y 4,000 libros de los 5,000 de Nos idos de março, según datos facilitados por la editora, en consulta a través de correo electrónico.

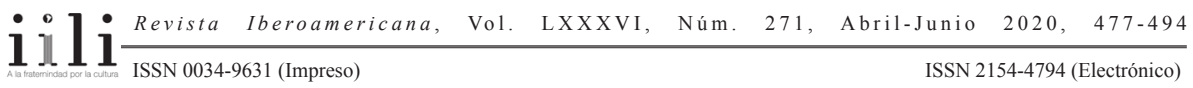


Even-Zohar, Itamar. "The 'Literary System"”. Poetics Today 11/1 (1990): 27-44.

Fittipaldi, Mário. "Feiras do livro. O hemisfério norte e o hemisfério sul”. Leia livros (1980): 7.

Franco, Renato. "Censura e modernização cultural à época da ditadura." Perspectivas 20-21 (1997-1998): 77-92.

Hollanda, Heloísa Buarque de, y Marcos A. Gonçalves. Política e literatura: a ficção da realidade brasileira. Rio de Janeiro: Europa, 1980.

Jornal do Brasil. "Uma década de muitos livros". Jornal do Brasil (29 dic 1979): 27. Jucá, Cecília. “Livro: objeto gráfico”. José (1976): 42.

Lajolo, Marisa, y Regina Zilberman. O preço da leitura. Leis e números por detrás das letras. São Paulo: Ática, 2001.

Lopes, Maria da Glória. "Livro, um produto condenado a sobrevivente." O Estado de São Paulo (1980): 44.

Lucas, Fábio. "O conto no Brasil moderno.” O livro do Seminário. Domício Proença Filho, org. São Paulo: LR Editores, 1983. 103-64.

Maués, Eloísa Aragão. "A editora Alfa-Omega nos anos de chumbo: entrevista com Fernando Mangarielo". Oralidades 2 (2007): 155-71. <http://www.revistas.usp. br/oralidades/article/view/106831/105481>. 2 sept. 2016.

Maués, Flamarión. "Livros, editoras e oposição à ditadura." Estudos Avançados 28/80 (2014): 91-104. <http:/l/www.revistas.usp.br/oralidades/article/ view/106831/105481>. 5 sept. 2016.

Medina, Cremilda. "Escritores na conquista do grande mercado." O Estado de São Paulo (4 sept. 1977): 12.

Neto, Leonardo. “Os dois lados do efeito Ruffato". Publishnews. 1 marzo 2016. <http:// www.publishnews.com.br/materias/2016/03/01/o-outro-lado-do-efeito-ruffato>. 22 sept. 2016.

Pellegrini, Tânia. Gavetas vazias. Ficção e política nos anos 70. Campinas: Mercado das Letras, 1996.

"Relíquias da casa velha: literatura e ditadura militar, 50 anos depois". Estudos de literatura brasileira contemporânea 43 (2014): 151-78.

Pereira, Helena Bonito. "Ficção brasileira censurada nos anos 70." Literatura e autoritarismo 10 (2012): 96-110.

Poppovic, Pedro Paulo. "Um falso problema: cultura ou mercadoria." Leia livros (1978): 22.

Reimão, Sandra. Mercado editorial brasileiro, 1960-1990. São Paulo: Com-Arte FAPESP, 1996.

“"Proíbo a publicação e circulação...'. Censura a livros na ditadura militar”. Estudos avançados 28/80 (2014): 75-90.

Reimão, Sandra, Flamarión Maués y Elias Nery. “Alfa-Ômega: o pensamento crítico em livro". Intercom-RBCC 38/1 (2015): 169-90.

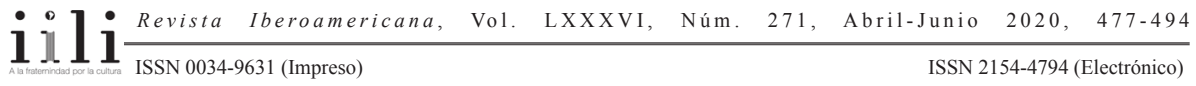


Ridenti, Marcelo. Em busca do povo brasileiro: artistas da Revolução, do CPC à era da TV. Rio de Janeiro: Record, 2000.

Ruffato, Luiz. Nos idos de março. A ditadura militar na voz de 18 autores brasileiros. São Paulo: Geração Editorial, 2014.

"Por que ler Emediato. Hoje?" Trevas no paraíso. Histórias de amor e guerra nos anos de chumbo. Luiz Fernando Emediato, org. São Paulo: Geração Editorial, 2004. 9-17.

Santiago, Silviano. "Memorialismo e ficção nos anos 80". Jornadas literárias. Oprazer do diálogo entre autores e leitores. Tânia M. Rösing y Vera Teixeira Aguiar, orgs. Passo Fundo: Prefeitura Municipal y Universidade de Passo Fundo, 1991. 249-54. Vale quanto pesa: ensaios sobre questões político-culturais. Rio de Janeiro: Paz e Terra, 1982.

Silva, Cláudio Humberto Rosa e. Mil dias de solidão. Collor bateu e levou. São Paulo: Geração Editorial, 1993.

Silverman, Malcolm. Protesto e o novo romance brasileiro. Carlos Araújo, trad. Porto Alegre: Editora da UFScar, 1995.

Süssekind, Flora. Literatura e vida literária: polêmicas, diários \& retratos. Rio de Janeiro: Jorge Zahar, 1985.

"V Bienal do Livro de São Paulo". Leia livros 1 (1978): 2.

Villarino Pardo, M. Carmen. "Eles eram muitos cavalos no(s) processo(s) de profissionalização de Luiz Ruffato". Uma cidade em camadas. Marguerite Harrison, org. Vinhedo: Horizonte, 2007. 155-87.

"Encontros de escritores brasileiros nos finais da década de 1970: um mecanismo de institucionalização e de mercado." Estudos de Literatura Brasileira Contemporânea 23 (2004): 151-68.

"O espaço do sistema literário brasileiro contemporâneo nos intercâmbios culturais transnacionais." Espaços possíveis na literatura brasileira contemporânea. Regina Dalcastagnè y Luciene Azevedo, orgs. Porto Alegre: Zouk Editora, 2015. 265-86. Zilberman, Regina. "Brasil: Cultura e Literatura nos Anos 80.” Organon 17/17 (1991): 93-104.

"Desafios da literatura brasileira na primeira década do séc. XXI." Nonada. Letras em Revista 15 (2010): 183-200.

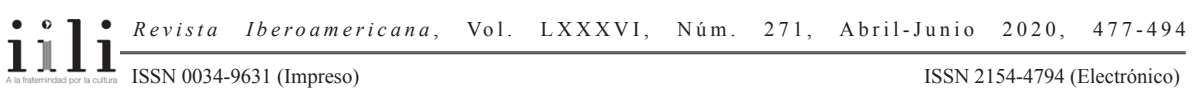


Palavras-chave: Luiz Ruffato; mercado editorial; ficción y política; cuentos; posdictadura

Recebido: $\quad 7$ novembro 2016

Aprovado: $\quad 15$ maio 2017 